\title{
CONTRIBUIÇÕES PARA A HISTÓRIA E A HISTORIOGRAFIA \\ DA EDUCAÇÃO RURAL, DO RURALISMO PEDAGÓGICO E DA EDUCAÇÃO DO CAMPO
}

\author{
Resenha do livro: \\ BEZERRA NETO, LUIZ. Educação rural no Brasil: do ruralismo pedagógico ao \\ movimento por uma Educação do Campo. Uberlândia: Navegando Publicações, 2016.
}

\section{Resenhado por: Cláudio Rodrigues da Silva}

O livro Educação rural no Brasil: do ruralismo pedagógico ao movimento por uma Educação do Campo é de autoria de Luiz Bezerra Neto, Professor da Universidade Federal de São Carlos (Ufscar), coordenador do Grupo de Estudos e Pesquisas sobre Educação no Campo (Gepec), e uma das referências, no Brasil, em pesquisas sobre o Movimento dos Trabalhadores Rurais Sem Terra (MST), sobre Educação no Campo, sobre Educação Rural e sobre o Ruralismo Pedagógico, Movimento atuante principalmente na primeira metade do século XX e que, conforme o autor, tinha como marca fundamental evitar, por meio de uma pedagogia específica para o campo, o êxodo dos trabalhadores rurais para as cidades.

Esse livro é resultante da Tese de Doutorado do autor, intitulada Avanços $e$ retrocessos da educação rural no Brasil, defendida em 2003, na Faculdade de Educação da Universidade Estadual de Campinas, sob orientação do Prof. Dr. José Claudinei Lombardi. A obra, fundamentada num amplo conjunto de fontes de diferentes acervos ou bancos de dados, é referência, em especial no que se refere à Educação Rural ou ao Ruralismo Pedagógico. Inclusive para preservar a originalidade, o autor optou por realizar sucintas alterações em relação ao texto original da Tese, que reflete um momento específico do seu pensamento.

O objetivo geral do livro é realizar uma análise acerca das concepções de educação defendidas ou levadas a termo pelo Ruralismo Pedagógico e pelo MST e estabelecer relações entre essas concepções, identificando avanços, retrocessos ou permanências na Educação Rural no Brasil.

O livro, publicado em 2016 pela Navegando Publicações e disponível para download gratuitamente no site dessa Editora ${ }^{\mathrm{i}}$, é composto por 190 páginas e apresenta, além da Introdução, das Considerações finais e das Referências, três capítulos.

No primeiro capítulo, intitulado $O$ ruralismo pedagógico e as propostas nacionalistas, Bezerra Neto apresenta uma retomada histórica sobre o Ruralismo Pedagógico, problematizando o contexto da gênese e da atuação desse Movimento, seus principais teóricos, objetivos e pressupostos, entre outras questões. Este capítulo é composto pelos seguintes tópicos: $O$ ruralismo pedagógico e a fixação do homem no campo; $O$ ruralismo pedagógico e a defesa do nacionalismo; $O$ ruralismo pedagógico no exterior; e A fixação do professor e do aluno no campo.

No segundo capítulo, As reformas educacionais frente as permanências e rupturas do ruralismo pedagógico, Bezerra Neto aborda, entre outras questões, aspectos das políticas e de práticas educativas recorrentes nas primeiras décadas do século $\mathrm{XX}$ no Brasil, inclusive no que tange à formação de professores para atuação em escolas rurais. $\mathrm{O}$ autor estabelece relações entre a questão das reformas educacionais e as demandas políticas, culturais e econômicas, em especial no que se refere ao desenvolvimento das forças produtivas naquele momento histórico, marcado pela crescente participação da indústria na economia brasileira. Compõem este capítulo os seguintes tópicos: A educação 
nas primeiras décadas do período Republicano; $O$ ruralismo pedagógico e as reformas educacionais; A escola do homem do meio rural; e A educação rural e urbana: a dicotomia do processo.

No terceiro capítulo, denominado O MST frente as propostas do ruralismo pedagógico, Bezerra Neto realiza uma análise sobre as concepções de educação do MST e do Ruralismo Pedagógico, destacando a questão dos avanços e dos retrocessos na Educação Rural no Brasil. O autor defende que há algumas permanências, especialmente no que tange às demandas por curso de formação de professores e currículo específicos para o campo e à implementação de ações teórico-práticas visando evitar o êxodo dos trabalhadores rurais para as cidades. Os tópicos que compõem este capítulo são: A relação entre a educação ruralista e o Movimento Sem-Terra; As relações entre reforma agrária e educação a partir do MST e dos ruralistas; As escolas rurais e a luta por um saber específico; A implantação e o desenvolvimento das escolas normais e normais rurais; e A importância do ensino técnico para o homem do campo.

Das Considerações finais, destacam-se alguns dos principais apontamentos do autor. Para Bezerra Neto há uma relação intrínseca entre educação e sociedade. Assim, educação é indissociável e, portanto, condicionada pelas relações políticas, culturais e, principalmente, econômicas da sociedade que a concebe, pois, em última instância, o modo de produção determina essas relações. Assim, torna-se inviável a apresentação da educação como restrita à dimensão pedagógica ou como panaceia. Portanto, apenas uma pedagogia específica não é suficiente para se evitar o êxodo dos trabalhadores rurais.

Bezerra Neto aponta algumas permanências que atingem principalmente a Educação Rural, como, por exemplo, a recorrente alegação, por governantes ou gestores estatais, de insuficiência ou de inexistência de recursos financeiros e a constante aplicação da lógica do custo-benefício, que tendem a impactar negativamente no processo de escolarização dos trabalhadores rurais. $\mathrm{O}$ autor registra, ainda, a ausência, a incipiência ou a insuficiência - inclusive no que se refere à área da educação - de políticas ou de equipamentos públicos de uso coletivo no campo, o que pode ter implicações diretas ou indiretas para o êxodo de trabalhadores rurais para as cidades, êxodo esse não raramente relacionado à busca de melhores condições de vida ou mesmo de sobrevivência.

No entanto, a ênfase de Bezerra Neto recai no que ele denomina reminiscências do Ruralismo Pedagógico nos discursos ou propostas de movimentos sociais do campo na atualidade. Entre essas reminiscências estão as demandas por curso de formação de professores e por currículo adequados às especificidades do campo e ações teórico-práticas visando evitar o êxodo dos trabalhadores rurais. Para o autor, essas demandas, que já foram apresentadas pelos Ruralistas Pedagógicos na primeira metade do século XX, continuam a ser postuladas pelo Movimento Nacional por uma Educação do Campo e, principalmente, pelo MST.

Para fins de contribuição para o debate, considera-se relevante e oportuna a publicação desse livro, que ocorre numa conjuntura marcada, no Brasil, pelo acirramento das lutas de classes no campo, lutas essas que repercutem necessariamente na educação escolar, fato que demanda ações teórico-práticas das classes trabalhadoras, em especial as do campo, área historicamente marcada por altos percentuais de analfabetismo ou de reduzidos índices de escolaridade, se estabelecidas relações com percentuais registrados nas cidades.

Bezerra Neto aborda polêmicas históricas, que envolvem pautas presentes resguardadas, entre outras, as devidas especificidades históricas, geográficas ou ideológicas - desde o século XIX, em debates de alguns dos principais Movimentos das classes trabalhadoras, como, por exemplo, anarquistas, cartistas, marxistas, socialistas 
utópicos owenistas e, na atualidade, o MST e o Ejército Zapatista de Liberación Nacional (EZLN).

Entre essas pautas estão, por exemplo: a) a concepção de currículo, uma questão historicamente em disputa, já que ele necessariamente veicula ideologias ou visões de mundo; b) o caráter e a finalidade da educação, ou seja, se a educação é um meio para determinado fim ou se é um fim em si mesma; c) a demanda pelo ensino de conhecimentos socialmente úteis, que atendam às necessidades das classes trabalhadoras, seja no sentido material seja no simbólico, tanto na dimensão imediata quanto na mediata; d) quem concebe, gere ou executa a educação das classes trabalhadoras?

$\mathrm{O}$ autor aborda também polêmicas do tempo presente, como, por exemplo, a demanda por formação docente e por currículos adequados às singularidades dos povos do campo. Isso remete aos debates em torno das concepções de educação para, no ou do campo, um debate candente na atualidade. Um dos principais protagonistas de iniciativas relacionadas à Educação do Campo é o MST, cujos intelectuais orgânicos apresentam a Educação do Campo e a Educação Rural como antagônicas, sendo a primeira entendida como organicamente vinculada aos povos do campo e a segunda apresentada como uma educação para o campo, vinculada organicamente ao capital.

No entanto, o ponto mais polêmico é o fato de o autor apresentar demandas postuladas pelo MST como reminiscências do Ruralismo Pedagógico, estabelecendo relações de semelhança entre demandas desses Movimentos. Se, por um lado, esses Movimentos apresentam preocupações com o êxodo para as cidades, requerem formação de professores e currículo adequados às especificidades do campo e tecem críticas ao ensino oficial estatal e ao latifúndio, por outro lado, tanto as suas críticas ou demandas quanto as suas táticas ou estratégicas são antagônicas, pois as suas visões de mundo são antagônicas.

Isso porque o Ruralismo Pedagógico, vinculado a frações das classes dominantes, operava numa lógica conservadora, não questionando nem se opondo ao modo de produção capitalista. Já o MST luta por transformações sociais conjunturais ou estruturais, com vistas, em última instância, ao socialismo. Assim, inclusive suas concepções de educação e de trabalho são antagônicas, ou seja, o primeiro Movimento visa o disciplinamento, enquanto o segundo visa a emancipação das classes trabalhadoras.

Essas polêmicas colocam em tela a pertinência de aprofundamentos teórico-práticos em torno dessas e de outras questões históricas que, desde o século XIX, perpassam debates e experiências de autoeducação das classes trabalhadoras.

A temática abordada no livro é atual, demandando pesquisas não apenas para fins de contribuição para o preenchimento de lacunas na história ou na historiografia da Educação Rural, em especial sobre o Ruralismo Pedagógico, como também para os debates em torno da Educação do Campo.

\footnotetext{
${ }^{\mathrm{i}}$ http://www.editoranavegando.com/
} 